\title{
Çukurova Bölgesinde Bazı Nohut (Cicer arietinum L.) Çeşit ve Hatlarında Verim ve Kalite Özelliklerinin Değerlendirilmesi
}

\author{
Dürdane MART ${ }^{1 *}$, Meltem TÜRKERI ${ }^{1}$, Ramazan $_{\text {AKIN }}^{2}$, Derya YÜCEL ${ }^{3}$, \\ Sezgin MART ${ }^{4}$ \\ ÖZ
}

Bu çalışma, Çukurova bölge koşullarında 2014-2015 yetiştirme yıllarında nohut (Cicer aritinum L.) çeşit sslahı amacıyla hat ve çeşitlerin ekimleri yapılarak verim ve verimle ilgili bazı özellikler incelenmiştir. Denemeler, Doğu Akdeniz Tarımsal Araştırma Enstitüsü Doğankent lokasyonunda, 20 genotip ile kışlık olarak ekilerek değerlendirilmiştir. Araştırmanın yürütüldüğü yılllarda kışlık ekimlerden elde edilen en yüksek tane verim değeri birinci ve ikinci yılda, 321.2 ve $297.4 \mathrm{~kg} / \mathrm{da}$, olarak İnci çeşidinden elde edilmiştir. 100 tane ağırlı̆̆ bakımından birinci yılda genotipler 53,234,4 gr; ikinci yılda 47.5-31.1 gr değerleri arasında değişim göstermiștir. Bunlara ilave olarak çiçeklenme, bakla bağlama, bitki boyu ve ilk bakla yüksekliği özellikleri de seleksiyon kriteri olarak değerlendirilmiştir. Araştırmanın yürütüldüğü yıllarda hat ve çeşitler üzerinde iklime bağlı yağışlar ve dağılımları önemli olmuştur. Ayrıca bu çeşit adaylarının hastalık bahçelerinde Antraknoz gözlemleri de incelenmiş ve hastalığa toleranslı olarak da tespit edilmiştir. 2014 ve 2015 her iki yetiştirme sezonu kalite değerleri bakımından ortalama Protein Analiz değerleri ise en yüksek FLIP 03-21C çeşidinden \% 21.48, en düşük değer ise X201 TH 165 line \% 19.15 değerleri elde edilmiştir. Adana1 çeşidi kuru ağırlık, yaş ağırlık, su alma kapasitesi, kuru hacim, yaş hacim, şişme kapasitesi bakımından diğer çeşitlere göre yüksek değerler vererek dikkati çekmiştir.

Anahtar Kelimeler: Nohut, Islah, Adaptasyon ve Kalite

Evaluation of yield and quality characteristics of some Chickpea (Cicer arietinum $L$.) lines and varieties in the region of Çukurova

\section{ABSTRACT}

In this research, the chickpea (Cicer arietinum L.) lines and varieties were examined for their yield and quality performances in order to select for new chickpea varieties. The research was conducted during 2014-2015 in the region of Çukurova. The field trials were took place in the Eastern Mediterranean Agricultural Research Institute with using 20 chickpea genotypes under winter conditions. The highest yields were obtained from the chickpea variety 'Inci' in the both growing periods of 2014 and 2015 with being $321,2 \mathrm{~kg} / \mathrm{da}$ and $297,4 \mathrm{~kg} / \mathrm{da}$ respectively. The 100 -grain weights were ranged between 53,2-34,4 gr for the first year and between 47.5-31.1 gr for the second year. In addition, the flowering date, pod tying, plant height and the first pod height were also taken into account as a criteria for the selection. The disribution of rainfall was also effective on the performances of lines and varieties. Furthermore, the lines and the varieties were examined for their tolerance to Antrochnose in specific disease nurseries. The variety 'FLIP 03-21C' was showed the highest protein value being $21,48 \%$ and the line 'X201 TH 165' was the lowest being 19,15\% during the both growing periods of 2014 and 2015. On the other hand, the variety Adanal was highly promising for the parameters such as dry weight, wet weight, water intake capacity, dry volume, wet volume and swelling capacity.

Keywords: Chickpea, Breeding, Adaptation and Quality

ORCID ID (Yazar sirasina göre)

0000-0002-2944-1227, 0000-0001-5225-967X, 0000-0002-9955-9482, 0000-0002-7865-9900,

$0000-0002-8597-6269$

Yayın Kuruluna Geliş Tarihi: 28.05.2021

Kabul Tarihi: 28.12.2021

${ }^{1}$ Doğu Akdeniz Tarımsal Araştırma Enstitüsü-Adana

${ }^{2}$ Geçit KuşağıTarımsal Araştırma Enstitüsü-Eskişehir

${ }^{3}$ Şırnak Üniversitesi Ziraat Fakültesi-Şırnak

${ }^{4}$ Crop Science, Üniversity of Hohenheim -Stuttgard

*E-posta: durdanemart@yahoo.com 


\section{Çukurova Bölgesinde Bazı Nohut (Cicer arietinum L.) Çeşit ve Hatlarında Verim ve Kalite Özelliklerinin Değerlendirilmesi}

\section{Giriş}

Türkiye'de nohut (Cicer arietinum L.) 517. 785 ha ekim alanı, 630.000 ton üretimi, birim alandan alınan tane verimi ise $122.00 \mathrm{~kg} / \mathrm{da}$ 'dır (FAO, 2021). Yemeklik tane baklagiller ülkemizde insan beslenmesinde kullanilan ve önemli bitkisel protein kaynağı olan bitkilerdendir; Protein zenginlikleri \%22-26 bakımından insan ve hayvan beslenmesinde önemli temel besin maddelerindendir (Şehirali,1988). Nohut besin değerleri bakımından zengin oldukları gibi nodoziteleri ile de yetiştirildikleri toprağa olumlu, iyileştirici katk1ları bulunmaktadır. Eser (1978) nohut bitkisi, fakir topraklarda yetişebilen, yüksek sicaklığa ve kuraklığa mercimekten sonraki en fazla toleranslı baklagil bitkisidir. $\mathrm{Bu}$ nedenle kışlık tahıl - nadas ekim nöbetinde kurak bölgelerimizde ekim nöbetine girerek birim alan verimini artırmada ve nadas alanlarımızı daraltmada önemli bir yere sahip olduğunu vurgulamıştır.

Son y1llarda özellikle baklagillerde işleme, paketleme sanayi ve çeşitli leblebi yapımı ile gelișen bir sanayi kolu olması nohutun önemini arttırmaktadır. Yürütülen ıslah çalışmalarında hastalıklara özellikle Antraknoz (A. rabiei) hastalığına toleranslı, makinalı ekime ve hasata uygun, pazar değeri yüksek çeşitlerin geliştirilerek çiftçinin hizmetine sunulması 1slah amacımız olmaktadır. Nohut üretim amacinın yüksek verimli ve kaliteli tane ürünü elde edilmesi olması nedeniyle, yetiştirileceği bölgeye göre uygun çeşitlerin geliştirilmesi, üretimin ve kalitenin arttırılmasında önemli bir faktördür.

$\mathrm{Bu}$ araştırma, ileri çıkmış hatların bölge koșullarında denenerek hastalı toleransı ve kalite değerlerinin tespitine ve çeşit geliştirmeye yönelik çalışmadır. Geliştirilen nohut çeşitlerinin farklı bölgelerde, kışlık ve yazlık ekimlerde yer bulabilmeleri, yüksek verimli, hastalıklara, zararlılara dayanıklı/toleranslı olmaları ekim alanlarında ekonomik kayıpların önlenmesini sağlayacaktır. Antraknozla mücadelede en etkili yol dayanıklı veya toleranslı çeşitlerin kullanılmasıdır. Bu nedenle kışlık nohut çeşitlerinin antraknoza toleranslı veya dayanıklı olması önemli olmaktadır. Yazlık ekilen nohudun verimi yüksek sicaklık ve kuraklık streslerinden olumsuz şekilde etkilenmekte ve verim kayıpları yaşanmaktadır (Slim ve ark. 1993, Babagil G.E.2011, Bejiga ve ark. 1982).

\section{Materyal ve Yöntem}

Araştırmada, Nohut ileri çıkmış hat ve çeşitlerinin adaptasyonları amacıyla 2014-2015 yetiştirme yıllarında planlanan denemeler için, 20 adet nohut hat ve çeşitlerinin, Adana lokasyonunda kışlık (Aralık) olarak ekimleri yapılarak değerlendirilmiştir.

Gül ve ark. (2006), Nohut bitkisinin kışlık olarak yetiştirilme olanaklarının araştırılması amacıyla yürüttükleri çalışma sonucunda; kışa dayanıkl111 ğın standart çeșitte \% 55.42, diğer hatlarda $\% 70.91$ ile $\% 78.75$ arasinda değiştiğini, başta tane verimi olmak üzere kışlık nohut ile ilgili bir çok özelliğin yazlık ekimlere göre daha avantajlı, ayrıca verim özelliği ve makinalı hasada uygunluk açısından kışlık ekimlerin daha avantajlı olabileceğini bildirmişlerdir (Anlarsal ve ark.,1999; Mart ve ark.,2001,2006,2010,2015; Saxena, M.C., 1980, Tripathi ve ark.,1985).

2014 ve 2015 yetiştirme sezonunda Adana lokasyonunda 20 adet nohut genotipi ile tarla denemesi planlanarak; 17 ileri çıkmıș hat ve 3 kontrol ile deneme yürütülmüştür. $\mathrm{Bu}$ araştırmada ekimler, sıra aras $10,45 \mathrm{~m}$, sıra üzeri $8 \mathrm{~cm}$ olacak şekilde, $5 \mathrm{~m}$ uzunluğundaki 4 sıraya ( $5 \mathrm{mX} 4$ sıraX0,45m olarak $9 \mathrm{~m}^{2}$ lik parsellere) üç tekerrürlü olarak ekimler yapılmıştır. Ekim öncesi dekara 2-3 kg N, 5-6 kg $\mathrm{P}_{2} \mathrm{O}_{5}$ gelecek şekilde gübreleme uygulanmış, Antraknoz yanıklığı hastalığına toleranslılıkları belirlemek için 1-9 (1=dayanıklı, 9=çok hassas) skalasında (Reddy and Singh, 1985; Chen ve ark., 2004) gerekli hastalık okumaları yapılmıştır.

2014 yılında, uzun yıllar ortalamasına göre yağışların az ve dengesiz dağılımı, yağış miktarının az olmasına rağmen, çiçeklenme ve bakla bağlama dönemi olan Mart ve Nisan aylarında düşen yağış miktarının ve sıcaklık ve nem oranlarinin uygun olmasi Ascocyhta yanıklığı hastalığının yoğunluğunun azalması üzerinde olumlu etkide bulunmuştur. 2015 yılında, uzun yıllara göre yağış miktarının düşük olmasına ragmen, nohut bitkisi için yağış yeterli olmuş ve çıkışlarda sorun yaşanmamıştır. $\mathrm{Bu}$ 


\section{Çukurova Bölgesinde Bazı Nohut (Cicer arietinum L.) Çeşit ve Hatlarında Verim ve Kalite Özelliklerinin Değerlendirilmesi}

yetiștirme sezonunda çiçeklenme dönemi olan Mart $(115,81 \mathrm{~mm})$ ayında yağış yoğunluğu nedeniyle, Ascocyhta yanıklı̆̆1 hastalığ yoğunluğu artmıştır. Mayıs $(81,02 \mathrm{~mm})$ ayındaki yoğun yağışlar da bakla bağlama dönemi başlangıcı olması nedeniyle Ascocyhta yanıklığı hastalığından dolayı hassas çeşitlerde parsel kayıpları yaşanmıştır. Yağış miktarı dağlımının düzensiz, düşük ve yüksek olması bitkileri strese sokmuş ve aynı zamanda da Ascocyhta yanıklığı hastalığının yoğunluğunda etkili olmuştur. Sicaklık ve nem değerleri ise uzun yıllar değerlerine paralel değerler göstermiştir 2014 ve 2015 her iki yetiştirme sezonunda nohut genotiplerinde kalite analizleri için, hasat sonrası denemelerdeki tekerrürler birleştirilerek iyice harman yapılıp kalite analizleri için örnekler alınmıştır (Çizelge 1).

Çizelge 1. Adana ili 2013-2014; 2014-2015 ve uzun yıllar iklim değerleri

\begin{tabular}{|c|c|c|c|c|c|c|c|c|c|}
\hline \multirow[t]{2}{*}{ Aylar } & \multicolumn{3}{|c|}{ Ortalama Sicaklık $\left(\mathrm{C}^{0}\right)$} & \multicolumn{3}{|c|}{ Yağış $(\mathrm{mm})$} & \multicolumn{3}{|c|}{ Nisbi nem (\%) } \\
\hline & Uz.Y1l & $2013-2014$ & $2014-2015$ & Uz.Y1l & 2013-2014 & $2014-2015$ & $\begin{array}{l}\text { Uz.Y } \\
11\end{array}$ & 2013-2014 & $2014-2015$ \\
\hline Kasım & 15.3 & 17,7 & 14,76 & 67,2 & 1,0 & 36,06 & 63 & 57,5 & 54,8 \\
\hline Aralık & 11.1 & 10,4 & 13,0 & 118,1 & 12,2 & 50,05 & 66 & 42,7 & 71,6 \\
\hline Ocak & 9.7 & 11,48 & 8,9 & 111,7 & 28,19 & 56,39 & 66 & 69,58 & 66,3 \\
\hline Şubat & 10.4 & 10,84 & 10,9 & 92,8 & 18,54 & 90,68 & 66 & 56,90 & 70,1 \\
\hline Mart & 13.3 & 15,06 & 13,9 & 67,9 & 56,09 & 115,81 & 66 & 65,55 & 64,6 \\
\hline Nisan & 17.5 & 17,68 & 15,8 & 51,4 & 18,56 & 7,88 & 69 & 66,94 & 62,5 \\
\hline Mayıs & 21.7 & 21,26 & 21,7 & 46,7 & 22,36 & 81,02 & 67 & 70,39 & 64,3 \\
\hline Haz. & 25.6 & 24,03 & 24,2 & 22,4 & 50,04 & 0 & 66 & 68,19 & 69,1 \\
\hline Tem. & 27,7 & 28,23 & 28,0 & 5,4 & 0,25 & 0 & 68 & 72,58 & 69,3 \\
\hline
\end{tabular}

\section{Bulgular ve Tartışma \\ Nohut Genotipleri verim ve Morfolojik özellikleri}

Denemede ortalama değerler ve oluşan gruplar Çizelge 1'de verilmektedir.

2014 yılı yetiştirme sezonunda, en yüksek ve en düşük değerler, çiçeklenme gün sayıs1 bakımından 57.0-67.3 gün, bakla bağlama gün say1s1 70.6-78.6 gün, bitki boyu $61.6-102.2 \mathrm{~cm}$, 100 tane ağırlığ $34.4-53.2 \mathrm{~g}$ ve tane verimi bakımından 54.2-321.2 kg/da değerleri arasında değişim göstermiş ve çeşitler arasında farklılık istatistiki düzeyde önemli olmuştur. 2014 y1lı yetiştirme sezonunda, çiçekleme tarihi bakımından en erkenci nohut çeşidi Hasanbey olurken bunu, FLIP-03-21C hattı ve EN 808 nohut hatlarının izledikleri saptanmıştır. Makinalı hasat bakımında önemli değerlendirme kriterleri olan İlk bakla yüksekliği bakımından ise çeşitler arasında önemli bir fark bulunmamaktadır. Bitki boyu bakımından, en yüksek bitki boyu değerine sahip nohut hattı X05 TH 69, olurken bunu, ENA 144-16, FLIP 0342C nohut hatlarının izledikleri saptanmıştır.
100 tane ağırlığı bakımından, en yüksek değer ise $53.2 \mathrm{~g}$ ile X05 TH 21 nohut hattından elde edilmiştir. 2014 yılı yetiştirme sezonunda, Adana1, EN 766, ENA 8-2, FLIP-03-42C, FLIP03-21C, X05 TH 80, X05 TH 69), X05 TH 21, X05 TH 21, ENA 144-11 nohut hatları ve Hasanbey çeşidinin, 40 g'ın üzerinde tane iriliğine sahip oldukları saptanmıştır. Tane verimi bakımından, Adana1, EN 808, FLIP 03108C, X05 TH 69, X05 TH 21, X05 TH 21, nohut hatları, Hasanbey, Seçkin ve İnci çeşitlerinin $200 \mathrm{~kg} / \mathrm{da}$ 'ın üzerinde tane verimine sahip oldukları saptanmıştır.

2015 yetiştirme sezonunda en düşük ve en yüksek değerler bakla bağlama gün sayısı125.0133.3 gün, ilk bakla yüksekliği $21.5-40.6 \mathrm{~cm}$, bitki boyu $54.4-87.7 \mathrm{~cm}, 100$ tane ağırlığı 31.1$47.5 \mathrm{gr}$ değerleri arasında dağılım gösterip çeşitler arasında istatistiki düzeyde önemli farklilıklar bulunmamakta; çiçeklenme gün sayıs1 106.7-114.7 gün ile Seçkin ve X201TH165 çeşitlerinde ve verim değerleri bakımından ise istatistiki olarak önemli farklılıklar olup; en düşük ve en yüksek değerler sirasiyla ve 29.1-297.4 kg/da ile ENA 8-2 ile İnci 


\section{Çukurova Bölgesinde Bazı Nohut (Cicer arietinum L.) Çeşit ve Hatlarında Verim ve Kalite Özelliklerinin Değerlendirilmesi}

çeşitlerinde gözlemlenmiştir. 2015 y1lı yetiştirme sezonunda, en erkenci nohut çeşidi Seçkin 106.67 gün olurken, FLIP03-108C hattı (107.84 gün) ve Hasanbey (109.33 gün) nohut çeşidini izledikleri saptanmıştır. En düşük bakla bağlama süresine Seçkin (125.0 gün) nohut çeşidi ve FLIP 03-108C hattı (125.0 gün) olurken bunu Ç-100-2-2 (127.3 gün) ve Hasanbey (128.0 gün) nohut hat/çeşidinin izledikleri belirlenmiştir. Bitki boyu bakımından, en yüksek bitki boyu değeri ENA 144-11 (87.20 cm) nohut hattından elde edilirken, bunu İnci $(87.19 \mathrm{~cm})$, FLIP 03-42C $(82.48 \mathrm{~cm})$ ve X05 TH $21(78.3 \mathrm{~cm})$ nohut hat/çeşidinin izledikleri belirlenmiştir. 100 tane ağırlığı bakımından, Adana1, EN 766, X05 TH 69), X05 TH 21, X05 TH 21 ve ENA 144-11 nohut hatlarının, $40 \mathrm{~g}$ '1n üzerinde tane iriliğine sahip oldukları saptanmıştır.

Tane verimi bakımından X05 TH 21 nohut hatt ve Hasanbey, Seçkin ve İnci çeşitlerinin 200 $\mathrm{kg} / \mathrm{da}$ 'ın üzerinde tane verimine sahip oldukları saptanmıştır. Adana Lokasyonunda, Ascocyhta yanıklığ 1 hastalığının yağış yoğunluğu nedeniyle doğal koşullarda görülmesi nedeniyle 100 tane ve verimler üzerinde olumsuz etkileri gözlenmiştir. Hastalıktan dolayı 100 tane ağırlıklarında düşük değerler tespit edilmiştir. $\mathrm{Bu}$ da verim kayıplarına neden olmuştur (Tablo2) (Nalçacı ve ark., 2021).

İki y1llı birleştirilmiş ortalamalara göre, çiçeklenme gün sayısı, bakla bağlama gün sayısı, bitki boyu, 100 tane ağırlığı ve tane verimi değerleri bakımından çeşitler arasında istatistiki düzeyde önemli farklılıklar olduğu belirlenmiştir. Projede yer alan nohut hat ve çeşitlerinin çiçeklenme gün sayısı değerlerinin 83.17-90.67, bakla bağlama gün sayıs1 99.33106.0 gün, ilk bakla yüksekliği 22.03-65.55 cm ve bitki boyu değerlerinin 64.15-87.20 cm, yüz tane ağırlığ 1 değerlerinin 33.68-50.08 g arasında değişim gösterdiği saptanmıştır. İki yıl ortalama verilerine göre Adana1, EN 766, FLIP-03-21C, X05 TH 69, X05 TH 21, X05 TH 21, ENA 14411 nohut hatları ve Hasanbey çeşidinin 40 g'1n üzerinde tane iriliğine sahip oldukları saptanmıştır. Ortalama tane verimi değerlerinin 45.52-309.33 kg/da arasında değişim göstermiş ve FLIP 03-108C, FLIP 03-21C, X05 TH 21 nohut hatları ve Hasanbey, Seçkin ve İnci çeşitlerinin $200 \mathrm{~kg} / \mathrm{da}$ ' 1 üzerinde tane verimine sahip oldukları saptanmıştır. Nohutta bitki boyu ve dallanma durumu, özellikle bitkilerin ilk meyve yüksekliği ve yatmaya dayanıklılık durumu makinalı hasat açısından önem taşımaktadır. Çeşit adaylarında aranan özellik genellikle yukarıdan bakla bağlayan, sağlam saplı, yatmaya dayanıklı ve yüksek verimli olmasıdır. $\mathrm{Bu}$ bağlamda eldeki nohut hatları arasında bitki boyu ve ilk bakla yüksekliği yönünden üzerinde durulması gereken ıslah materyalleri mevcuttur.

Birinci y1lda Adana lokasyonunda, Ascocyhta yanıklığı hastalığının yoğun görülmemesi nedeniyle verimler üzerinde olumsuz bir etki gözlenmemiştir. İkinci yılda yağış miktarının daha fazla olması ve özellikle çiçeklenme dönemine denk gelmesi denemeye alınan tüm nohut genotiplerinde antaknoz yanıklığ1 hastalığının orta ve şiddetli düzeyde görülmesine yol açmıştır.

Ascochyta yanıklığı hastalığının yoğunluğuna bağlı olarak hat ve çeşitlerin 100 tane ağırlığ1 değerleri ve tane verimlerinde önemli azalmalar tespit edilmiştir (Çizelge 2). Kışlik olarak ekilecek nohut çeşitlerinin kışa ve Ascocyhta yanıklığı hastalığına tolerans/dayanıklılığının yüksek olması gerekmektedir ((Nalçacı ve ark.,2021, Kocalar ve ark2020, Bakoğlu, 2009, Mart ve ark, 2001; Açıkgöz, 1987).

\section{Nohut Genotipleri Kalite Değerleri}

Doğu Akdeniz Tarımsal Araştırma Enstitüsünde daha önce yapılan çalışmalarda öne çıkmış toplam 17 hat ile Hasanbey, Seçkin ve İnci çeşitleri kontrol çeşit olarak kullanılmıştır. Kalite analizleri için denemede tekerrürler birleştirilerek iyice harman yapılıp örnekler alınmıştır. Adana ileri Hatlar verim denemesine ait kalite sonuçları ortalama değerleri Çizelge 34'de verilmiştir.

2014 y1lı yetiştirme sezonunda Çizelge 3'den görüleceği üzere Adana lokasyonunda kalite sonuçları bakımından en düşük ve en yüksek kuru ağırlık değerleri 39,29-59,72g; yaş ağırlık değerleri 75,18-115,27g; su alma kapasitesi 0,36-0,56g/tane; su alma indeksi \%0,91-1,08; kuru hacim değerleri $80-96 \mathrm{ml}$; yaş hacim değerleri 166-203ml; şişme kapasitesi 0,36-0,57 $\mathrm{ml} /$ tane; şişme indeksi \%2,20-2,45 değerleri 


\section{Çukurova Bölgesinde Bazı Nohut (Cicer arietinum L.) Çeşit ve Hatlarında Verim ve Kalite Özelliklerinin Değerlendirilmesi}

arasında değişim gösterdikleri tespit edilmiştir. Elek analiz değerleri ise 9 nolu elekte \%11,2389,$92 ; 8$ nolu elekte $\% 9,97-73,57 ; 7$ nolu elekte $\% 0,74-36,52 ; 6$ nolu elekte \%0,00-6,56 değerleri arasında değişim gösterdikleri belirlenmiştir. Protein analiz değerlerinden ise en yüksek değer X05 TH 21 hattından \%23,75, en düşük değer ise X201 TH165 hattından \%20,00 değerleri elde edilmiştir ve bu değerler arasında değişim gösterdikleri belirlenmiştir.

2015 yılı kalite sonuçları bakımından en düşük ve en yüksek kuru ağırlık değerleri 33,36-54,4g; yaş ağırlık değerleri 65,18-106,48g; su alma kapasitesi 0,32-0,52 g/tane; su alma indeksi $\% 0,94-1,09$; kuru hacim değerleri 73-93ml; yaş hacim değerleri 156-196ml; şişme kapasitesi 0,33 - $0,53 \mathrm{ml} /$ tane; şişme indeksi $\% 2,22-2,43$ değerleri arasında değişim gösterdikleri tespit edilmiștir. Elek analiz değerleri ise 9 nolu elekte $\% 12,46-70,01 ; 7$ nolu elekte \%0,6319,87değerleri arasında değişim gösterdikleri belirlenmiştir. Protein analiz değerlerinden ise en yüksek FLIP $03108 \mathrm{C}$ hattından \% 20.69, en düşük ENA 144-11 hattından \% 17.57 değerleri elde edilmiş ve bu değerler arasında değişim gösterdikleri belirlenmiştir. Singh ve ark. (1990), ICARDA'dan temin ettikleri kabuli nohut genotiplerinde 100 tane ağırlığı, protein miktarı ve pişme zamanı sürelerini belirlemek üzere yaptıkları araştırmada, 100 tane ağırlığının 8 ile $67 \mathrm{~g}$, protein miktarının \% 14.3 ile \% 27 ve pişme süresinin 50 dakika ile 296 dakika arasında değiştiğini bildirmişlerdir. Ayrıca protein miktarının yetiştirme sezonunda meydana gelen iklim olaylarına göre değişebileceğini ifade etmişlerdir.

2014-2015 iki yıllık ortalama değerlere göre Tablo3'den görüleceği üzere Adana lokasyonunda kalite sonuçları bakımından en düşük ve en yüksek kuru ağırlık değerleri 36.33$56.83 \mathrm{~g}$; yaş ağırlık değerleri $85.89-110.66 \mathrm{~g}$; su alma kapasitesi $0.34-0.54 \mathrm{~g} / \mathrm{tane}$; su alma indeksi \%0,93-1,09; kuru hacim değerleri 76.5-94.5ml; yaş hacim değerleri 161.0-199.5ml; şişme kapasitesi $0,35-0,55 \mathrm{ml} /$ tane; şişme indeksi $\% 2,24-2,42$ değerleri arasında değişim gösterdikleri tespit edilmiştir.
Elek analiz değerleri ise 9 nolu elekte \%12,13$87.26 ; 8$ nolu elekte $\% 12,46-70,01 ; 7$ nolu elekte \%0.63-19.87 değerleri arasında değișim gösterdikleri belirlenmiştir. Elek değerleri özellikle de 9 nolu elek değeri ne kadar yüksek olursa nohutun fiyatlandırılmasında pazar değeri üzerinde pozitif yönde etkili olmaktadır. Protein analiz değerlerinden ise en yüksek değer FLIP 03-21C hattından \%21,48, en düşük değer ise X201 TH165 hattından \%19.15 değerleri elde edilmiştir ve bu değerler arasında değişim gösterdikleri belirlenmiştir. Bu çalışmada yer alan hatlar arasında Adana1 hattı kuru ağırlık, yaş ağılık, su alma kapasitesi, şişme indeksi bakımından; elek analizlerinden 9 nolu elekte de, X05 TH 21-2 hattı diğer hatlara göre en yüksek değerleri vererek ön plana çıkmışlardır. Atiky1lmaz (1997) yetiştirme sezonunda meydana gelen iklim olaylarına göre protein oranının da değiştiğini tespit etmişlerdir.

\section{Sonuç}

$\mathrm{Bu}$ çalışma ile, ileri çıkmış nohut (Cicer aritinum L.) genotiplerinin Doğu Akdeniz Bölgesi iklim koşullarında bölgesel adaptasyonları ve Ascochyta yanıklığına karşı tolerans/dayanıklılıkları araştırılmıştır. Adana lokasyonunda, yıllık yağ 1 ș miktarı $550-600 \mathrm{~mm}$ olmas1 nedeniyle Ascocyhta yanıklığ 1 hastalığının doğal koşullarda her yıl görülmesi nedeniyle 100 tane ve verimler üzerinde olumsuz etkileri gözlenmektedir. Bu çalışmada yıllara ve iki yıllık ortalamalara göre tane verimi, hastalık toleransı ve diğer özellik değerleri bakımından bölge çeşitleri (İnci-HasanbeySeçkin) ileri çıkmıştır. Bununla birlikte ileri çıkmış hatlardan da ADANA1, FLIP 03-108C, FLIP 03-21C, X05 TH 69, X05 TH 21-1, X05 TH 21-2 hatları çeşit adayları olarak sslah çalışmalarında değerlendirilmeye alınmışlardır (Şehirali, 2002, Reddy ve ark., 1990). Birinci y1l Ascochyta yanıklığı çok etkili olmamasına rağmen ikinci yıl olumsuz etkide bulunmuştur. Nohut bitkisinde tane iriliği ile Ascochyta yanıklığı arasında ters ilişki bulunmaktadır. Tane irileştikçe hassaslık artar, tane küçüldükçe de dayanıkl11ık artar (Mart, 2006; Muehlbauer ve ark. 1987, Phadnis, ve ark.1970). 
Çukurova Bölgesinde Bazı Nohut (Cicer arietinum L.) Çeşit ve Hatlarında Verim ve Kalite Özelliklerinin Değerlendirilmesi

Çizelge 2. Adana Lokasyonunda Bazı Nohut Hatlarında Verim ve Morfolojik Özellik Değerleri (2014-2015)

\begin{tabular}{|c|c|c|c|c|c|c|c|c|c|c|c|c|c|c|c|c|c|c|c|c|c|}
\hline \multirow[t]{2}{*}{$\begin{array}{l}\text { Sira } \\
\text { No }\end{array}$} & \multirow[t]{2}{*}{$\begin{array}{l}\text { Hat ve } \\
\text { Çeşitler }\end{array}$} & \multicolumn{3}{|c|}{$\begin{array}{l}\text { Çiçeklenme Gün Sayısı } \\
\text { (gün) }\end{array}$} & \multicolumn{2}{|c|}{ Ascochyta (1-9) } & \multicolumn{3}{|c|}{ Bakla Băg Gün Sayısı (gün) } & \multicolumn{3}{|c|}{ İlk bakla Yüksekliği $(\mathrm{cm})$} & \multicolumn{3}{|c|}{$\begin{array}{c}\text { Bitki Boyu } \\
(\mathrm{cm})\end{array}$} & \multicolumn{3}{|c|}{$\begin{array}{c}100 \text { Tane Ağrrlı̆̆ } \\
\text { (gr) }\end{array}$} & \multicolumn{3}{|c|}{$\begin{array}{c}\text { Tane Verim } \\
(\mathrm{kg} / \mathrm{da})\end{array}$} \\
\hline & & 2014 & 2015 & Ort. & 2014 & 2015 & 2014 & 2015 & Ort. & 2014 & 2015 & Ort. & 2014 & 2015 & Ort. & 2014 & 2015 & Ort. & 2014 & 2015 & Ort. \\
\hline 1 & ADANA1 & $59,3 \mathrm{EF}$ & $111 \mathrm{AB}$ & 85,17B-D & $1-3$ & 6 & $73,3 \mathrm{AB}$ & 130,0 & $101,67 \mathrm{AB}$ & 22,2 & 33,9 & $28,04 \mathrm{AB}$ & $67,7 \mathrm{~B}$ & 72,2 & 69,99 & $45,4 \mathrm{AC}$ & 47,5 & $46,47 \mathrm{AB}$ & $200,5 \mathrm{AE}$ & $153,9 \mathrm{AB}$ & 177,19A-E \\
\hline 2 & X201 TH165 & $66,6 \mathrm{AB}$ & $114,67 \mathrm{~A}$ & $90,67 \mathrm{~A}$ & $4-4$ & 8 & $78,6 \mathrm{~A}$ & 133,3 & 106A & 24,9 & 26,6 & $25,82 \mathrm{AB}$ & $74,4 \mathrm{AB}$ & 65,5 & 69,97 & $36,2 \mathrm{CE}$ & 31,1 & $33,68 \mathrm{E}$ & $54,2 \mathrm{E}$ & $36,7 \mathrm{~B}$ & $45,52 \mathrm{E}$ \\
\hline 3 & EN 808 & $59,3 \mathrm{EF}$ & $110 \mathrm{AB}$ & $84,67 \mathrm{CD}$ & 3-4 & 7 & $74,0 \mathrm{AB}$ & 128,0 & $101 \mathrm{AB}$ & 21,6 & 22,4 & $22,03 \mathrm{~B}$ & $79,4 \mathrm{AB}$ & 54,4 & 66,92 & $39,6 \mathrm{BE}$ & 39,1 & 39,40B-E & $204,8 \mathrm{AE}$ & $71,8 \mathrm{AB}$ & 138,33B-E \\
\hline 4 & EN 766 & $63,6 \mathrm{AE}$ & $112 \mathrm{AB}$ & $87,83 \mathrm{~A}-\mathrm{C}$ & 3-3 & 7 & $76,6 \mathrm{AB}$ & 130,7 & $103,67 \mathrm{AB}$ & 23,3 & 23,3 & $23,32 \mathrm{AB}$ & $72,7 \mathrm{AB}$ & 59,9 & 66,37 & $42,7 \mathrm{BE}$ & 40,9 & $41,86 \mathrm{~A}-\mathrm{E}$ & $185,7 \mathrm{AE}$ & $45,2 \mathrm{AB}$ & 115,48B-E \\
\hline 5 & EN 952 & $60,6 \mathrm{CF}$ & $111,33 \mathrm{AB}$ & 86B-D & 3-3 & 6 & $74 \mathrm{AB}$ & 131,3 & $102,67 \mathrm{AB}$ & 22,7 & 27,2 & $24,99 \mathrm{AB}$ & $78,3 \mathrm{AB}$ & 63,3 & 70,82 & $36,9 \mathrm{CE}$ & 38,6 & 37,20B-E & $173,2 \mathrm{AE}$ & $125,4 \mathrm{AB}$ & 149,33B-E \\
\hline 6 & C-100-2-2 & $58,6 \mathrm{EF}$ & $109,33 \mathrm{AB}$ & 87A-D & $3-4$ & 6 & $74,3 \mathrm{AB}$ & 127,3 & $100,83 \mathrm{AB}$ & 21,1 & 21,6 & $21,37 \mathrm{~B}$ & $73,8 \mathrm{AB}$ & \begin{tabular}{|l|l|}
58,8 \\
\end{tabular} & 66,36 & $34,4 \mathrm{E}$ & 36,5 & $35,45 \mathrm{DE}$ & $117,0 \mathrm{BE}$ & $125,3 \mathrm{AB}$ & 121,14B-E \\
\hline 7 & ENA 8-2 & $59,6 \mathrm{DF}$ & $114,33 \mathrm{~A}$ & $85,75 \mathrm{~A}-\mathrm{D}$ & $2-3$ & 8 & $74,0 \mathrm{AB}$ & 133,3 & $103,67 \mathrm{AB}$ & 23,3 & 40,5 & $31,94 \mathrm{AB}$ & $81,1 \mathrm{AB}$ & 69,4 & 75,26 & $42,0 \mathrm{BE}$ & 34,9 & $38,48 \mathrm{~B}-\mathrm{E}$ & $168,5 \mathrm{AE}$ & 29,1B & 98,85C-E \\
\hline 8 & FLIP 03-108 C & $63,6 \mathrm{AE}$ & $107,84 \mathrm{AB}$ & $87,17 \mathrm{~A}-\mathrm{D}$ & $1-3$ & 5 & $74,6 \mathrm{AB}$ & 125,0 & $100,21 \mathrm{AB}$ & 22,7 & 33,9 & $30,09 \mathrm{AB}$ & $83,8 \mathrm{AB}$ & 69,4 & 76,35 & $37,8 \mathrm{CE}$ & 39,5 & 38,48B-E & $257,7 \mathrm{AD}$ & $160,7 \mathrm{AB}$ & 230,81A-D \\
\hline 9 & FLIP $03-42 \mathrm{C}$ & $64,0 \mathrm{AE}$ & $110,33 \mathrm{AB}$ & $84 \mathrm{CD}$ & $2-3$ & 6 & $76,0 \mathrm{AB}$ & 130,3 & $103,1 \mathrm{AB}$ & 23,8 & 32,6 & $28,26 \mathrm{AB}$ & $85.0 \mathrm{AB}$ & 79,9 & 82,48 & $41,4 \mathrm{BE}$ & 36,5 & 38,97B-E & $90,2 \mathrm{CE}$ & $159,7 \mathrm{AB}$ & $125 \mathrm{~B}-\mathrm{E}$ \\
\hline 10 & FLIP $03-21$ C & $58,3 \mathrm{EF}$ & $110 \mathrm{AB}$ & $84,17 \mathrm{CD}$ & $3-3$ & 6 & $70,6 \mathrm{~B}$ & $\begin{array}{ll}128,7 \\
\end{array}$ & 99,67B & 20,5 & 33,3 & $26,93 \mathrm{AB}$ & $67,2 \mathrm{~B}$ & \begin{tabular}{|l|}
63,9 \\
\end{tabular} & $\begin{array}{l}65,54 \\
\end{array}$ & $41,4 \mathrm{BE}$ & 39,3 & 40,35B-E & $245,7 \mathrm{AD}$ & $169,1 \mathrm{AB}$ & 207,37A-D \\
\hline 11 & X05 TH 80 & $67,3 \mathrm{~A}$ & $111,33 \mathrm{AB}$ & $89,33 \mathrm{AB}$ & $3-4$ & 7 & $78,6 \mathrm{~A}$ & 130,3 & $104,5 \mathrm{AB}$ & 23,8 & $\begin{array}{ll}30,8 \\
\end{array}$ & $27,34 \mathrm{AB}$ & $62,2 \mathrm{~B}$ & 75,2 & 68,73 & $40,5 \mathrm{BE}$ & 34,9 & 37,74B-E & $88,1 \mathrm{CE}$ & $54,7 \mathrm{AB}$ & $71,40 \mathrm{DE}$ \\
\hline 12 & X05 TH 69 & $63,3 \mathrm{AE}$ & $110,67 \mathrm{AB}$ & 87A-D & $1-3$ & 7 & $74,0 \mathrm{AB}$ & 128,7 & $101,33 \mathrm{AB}$ & 32,7 & 31,1 & $31,94 \mathrm{AB}$ & $102,2 \mathrm{~A}$ & 72,2 & 71,39 & $48,8 \mathrm{AB}$ & 41,1 & $45,01 \mathrm{~A}-\mathrm{C}$ & $274,8 \mathrm{AC}$ & $66,8 \mathrm{AB}$ & 170,85A-E \\
\hline 13 & X05 TH 21-1 & $66,0 \mathrm{AC}$ & $110,67 \mathrm{AB}$ & $88,33 \mathrm{~A}-\mathrm{C}$ & $1-2$ & 6 & $78,6 \mathrm{~A}$ & 128,7 & $103,67 \mathrm{AB}$ & 23,8 & 31,1 & $27,50 \mathrm{AB}$ & $81,1 \mathrm{AB}$ & \begin{tabular}{|l|l|}
61,7 \\
\end{tabular} & 73,33 & $44,6 \mathrm{AD}$ & 42,0 & $43,35 \mathrm{~A}-\mathrm{D}$ & $259,1 \mathrm{AD}$ & $129,0 \mathrm{AB}$ & 194,11A-E \\
\hline 14 & X05 TH 21-2 & $65,3 \mathrm{AD}$ & $111 \mathrm{AB}$ & $88,17 \mathrm{~A}-\mathrm{C}$ & $1-2$ & 5 & $77,3 \mathrm{AB}$ & 129,3 & $103,33 \mathrm{AB}$ & 25,5 & 34,4 & $29,97 \mathrm{AB}$ & $75,5 \mathrm{AB}$ & \begin{tabular}{|l|}
71,1 \\
\end{tabular} & 78,03 & $53,2 \mathrm{~A}$ & 46,9 & $50,08 \mathrm{~A}$ & $255 \mathrm{AD}$ & $243,3 \mathrm{AB}$ & $249,18 \mathrm{~A}-\mathrm{C}$ \\
\hline 15 & ENA $144-10$ & $63,3 \mathrm{AE}$ & $112 \mathrm{AB}$ & 87,67A-D & 3-4 & 6 & $74,0 \mathrm{AB}$ & 131,3 & $102,67 \mathrm{AB}$ & 21,1 & 30,5 & $25,82 \mathrm{AB}$ & $76,6 \mathrm{AB}$ & 79,4 & 70,54 & $35,1 \mathrm{E}$ & 39,5 & 37,31C-E & $80,2 \mathrm{DE}$ & $143,3 \mathrm{AB}$ & 111,81C-E \\
\hline 16 & ENA $144-11$ & $61,0 \mathrm{BF}$ & $111,67 \mathrm{AB}$ & $86,33 \mathrm{~A}-\mathrm{D}$ & $3-3$ & 7 & $74,0 \mathrm{AB}$ & 131,0 & $102,5 \mathrm{AB}$ & 24,4 & 27,8 & $26,10 \mathrm{AB}$ & $75,5 \mathrm{AB}$ & 65,5 & 87,20 & $40,3 \mathrm{BE}$ & 41,1 & 40,73B-E & $132,2 \mathrm{AE}$ & $47,4 \mathrm{AB}$ & $89,81 \mathrm{DE}$ \\
\hline 17 & ENA $144-16$ & $63,0 \mathrm{AE}$ & $110,67 \mathrm{AB}$ & 86,83A-D & $3-4$ & 7 & 76,0 & 130,3 & 103,17 & 24,6 & 25,5 & $25,08 \mathrm{AB}$ & $86,6 \mathrm{AB}$ & 87,7 & 65,82 & $36,2 \mathrm{CE}$ & 39,6 & 37,91B-E & $111,5 \mathrm{BE}$ & $100,7 \mathrm{AB}$ & 106,11C-E \\
\hline 18 & HASANBEY & $57,0 \mathrm{~F}$ & $109,33 \mathrm{AB}$ & $83,17 \mathrm{D}$ & $1-3$ & 5 & $70,6 \mathrm{~B}$ & 128,0 & 99,33B & 96,1 & 35,0 & $65,55 \mathrm{~A}$ & $63,3 \mathrm{~B}$ & 68,3 & 69,17 & $42,8 \mathrm{BE}$ & 37,4 & 40,12B-E & $298,4 \mathrm{AB}$ & $232,7 \mathrm{AB}$ & $265,59 \mathrm{AB}$ \\
\hline 19 & SEÇKİN & $65,3 \mathrm{AD}$ & $106,67 \mathrm{~B}$ & 86B-D & $1-3$ & 4 & $77,3 \mathrm{AB}$ & 125,0 & $101,17 \mathrm{AB}$ & 24,4 & 36,1 & $30,25 \mathrm{AB}$ & $63,3 \mathrm{~B}$ & 75,0 & 64,15 & $40,4 \mathrm{BE}$ & 37,0 & 38,74B-E & $214,5 \mathrm{AE}$ & $283,0 \mathrm{AB}$ & 248,81A-C \\
\hline 20 & inCi & $63,3 \mathrm{AE}$ & $110,67 \mathrm{AB}$ & 87A-D & $1-3$ & 4 & $75,3 \mathrm{AB}$ & 129,3 & $102,33 \mathrm{AB}$ & 24,4 & 35,1 & $29,70 \mathrm{AB}$ & $61,6 \mathrm{~B}$ & 66,6 & 87,19 & $35,4 \mathrm{DE}$ & 33,4 & $34,40 \mathrm{DE}$ & $321,2 \mathrm{~A}$ & $297,4 \mathrm{~A}$ & $309,33 \mathrm{~A}$ \\
\hline \multicolumn{2}{|l|}{$\mathbf{F}$} & $* *$ & $*$ & $* *$ & & & $* *$ & ÖD & *** & ÖD & ÖD & ÖD & $* * *$ & ÖD & ÖD & $* * *$ & ÖD & $* *$ & *** & $* *$ & *** \\
\hline \multicolumn{2}{|c|}{ V.K.(\%) } & $\begin{array}{ll}3,08 \\
\end{array}$ & 19 & $\begin{array}{ll}1,89 \\
\end{array}$ & & & \begin{tabular}{ll|}
3,06 \\
\end{tabular} & 21 & 1,28 & 99,46 & 25 & $\begin{array}{ll}5,88 \\
\end{array}$ & 12,81 & 20 & $\begin{array}{l}8,76 \\
\end{array}$ & 7,33 & 12 & 1,25 & 32,94 & 61,3 & 116,29 \\
\hline \multicolumn{2}{|c|}{ TUKEY $(0,05)$} & & & & & & & & & & & & & & & & & & & & \\
\hline
\end{tabular}




\section{Çukurova Bölgesinde Bazı Nohut (Cicer arietinum L.) Çeşit ce Hatlarında Verim ve Kalite Özelliklerinin Değerlendirilmesi}

Çizelge 3. Adana Lokasyonunda Bazı Nohut Hatlarında Kalite Özellik Değerleri (2014-2015)

\begin{tabular}{|c|c|c|c|c|c|c|c|c|c|c|c|c|c|c|c|c|c|c|c|c|c|c|c|c|c|}
\hline \multirow[t]{2}{*}{$\begin{array}{l}\text { Sira } \\
\text { No }\end{array}$} & \multirow[t]{2}{*}{$\begin{array}{l}\text { Hat ve } \\
\text { Çeşitler }\end{array}$} & \multicolumn{3}{|c|}{$\begin{array}{c}\text { Kuru Ağırlık } \\
(100 \text { tane ağırlı̆̆ı)(g) }\end{array}$} & \multicolumn{3}{|c|}{$\begin{array}{c}\text { Yaş Ağırlık } \\
\text { (g) }\end{array}$} & \multicolumn{3}{|c|}{$\begin{array}{c}\text { Su Alma Kapasitesi } \\
\text { (g/tane) }\end{array}$} & \multicolumn{3}{|c|}{$\begin{array}{c}\text { Su Alma İndeksi } \\
(\%)\end{array}$} & \multicolumn{3}{|c|}{$\begin{array}{c}\text { Kuru Hacim } \\
(\mathrm{ml})\end{array}$} & \multicolumn{3}{|c|}{$\begin{array}{c}\text { Yaş Hacim } \\
(\mathrm{ml})\end{array}$} & \multicolumn{3}{|c|}{$\begin{array}{c}\text { Şişme Kapasitesi } \\
\text { (ml/tane) }\end{array}$} & \multicolumn{3}{|c|}{$\begin{array}{c}\text { Şişme İndeksi } \\
(\%)\end{array}$} \\
\hline & & 2014 & 2015 & Ort. & 2014 & 2015 & Ort. & 2014 & 2015 & Ort. & 2014 & 2015 & Ort. & 2014 & 2015 & Ort. & 2014 & 2015 & Ort. & 2014 & 2015 & Ort. & 2014 & 2015 & Ort. \\
\hline 1 & ADANA1 & 59,25 & 54,4 & 56,83 & 115,3 & 106,45 & 110,86 & 0,56 & 0,52 & 0,54 & 0,95 & 0,96 & 0,96 & 96 & 93 & 94,5 & 203 & 196 & 199,5 & 0,57 & 0,53 & 0,55 & 2,24 & 2,23 & 2,24 \\
\hline 2 & X201 TH165 & 41,30 & 43,62 & 42,46 & 84,1 & 88,52 & 86,32 & 0,43 & 0,45 & 0,44 & 1,04 & 1,03 & 1,04 & 81 & 82 & 81,5 & 175 & 177 & 176,0 & 0,44 & 0,45 & 0,45 & 2,42 & 2,41 & 2,42 \\
\hline 3 & EN 808 & 48,70 & 42,45 & 45,58 & 99,9 & 87,69 & 93,78 & 0,51 & 0,45 & 0,48 & 1,05 & 1,07 & 1,06 & 87 & 83 & 85,0 & 190 & 178 & 184,0 & 0,53 & 0,45 & 0,49 & 2,43 & 2,36 & 2,40 \\
\hline 4 & EN 766 & 51,74 & 41,18 & 46,46 & 101,8 & 86,2 & 94,02 & 0,50 & 0,45 & 0,48 & 0,97 & 1,09 & 1,03 & 90 & 82 & 86,0 & 190 & 177 & 183,5 & 0,5 & 0,45 & 0,48 & 2,25 & 2,41 & 2,33 \\
\hline 5 & EN 952 & 40,16 & 46,45 & 43,31 & 82,6 & 94,47 & 88,53 & 0,42 & 0,48 & 0,45 & 1,06 & 1,03 & 1,05 & 81 & 86 & 83,5 & 173 & 184 & 178,5 & 0,42 & 0,48 & 0,45 & 2,35 & 2,33 & 2,34 \\
\hline 6 & Ç-100-2-2 & 41,28 & 44,47 & 42,88 & 85,3 & 90,2 & 87,76 & 0,44 & 0,46 & 0,45 & 1,07 & 1,03 & 1,05 & 81 & 85 & 83,0 & 176 & 180 & 178,0 & 0,45 & 0,45 & 0,45 & 2,45 & 2,29 & 2,37 \\
\hline 7 & ENA 8-2 & 51,27 & 45,89 & 48,58 & 103,5 & 91,36 & 97,45 & 0,52 & 0,45 & 0,49 & 1,02 & 0,99 & 1,01 & 90 & 86 & 88,0 & 193 & 180 & 186,5 & 0,53 & 0,44 & 0,49 & 2,33 & 2,22 & 2,28 \\
\hline 8 & FLIP 03-108 c & 44,95 & 40,99 & 42,97 & 88,3 & 80,12 & 84,22 & 0,43 & 0,39 & 0,41 & 0,96 & 0,95 & 0,96 & 84 & 82 & 83,0 & 178 & 171 & 174,5 & 0,44 & 0,39 & 0,42 & 2,29 & 2,22 & 2,26 \\
\hline 9 & FLIP $03-42 \mathrm{c}$ & 48,41 & 42,41 & 45,41 & 100,7 & 88,79 & 94,68 & 0,52 & 0,46 & 0,49 & 1,08 & 1,09 & 1,09 & 87 & 83 & 85,0 & 188 & 178 & 183,0 & 0,51 & 0,45 & 0,48 & 2,38 & 2,36 & 2,37 \\
\hline 10 & FLIP 03-21 c & 48,35 & 41,31 & 44,83 & 96,71 & 84,69 & 90,70 & 0,48 & 0,43 & 0,46 & 1,00 & 1,05 & 1,03 & 87 & 82 & 84,5 & 186 & 174 & 180,0 & 0,49 & 0,42 & 0,46 & 2,32 & 2,31 & 2,32 \\
\hline 11 & X05 TH 80 & 49,12 & 39,81 & 44,47 & 99,8 & 84,15 & 91,98 & 0,51 & 0,44 & 0,48 & 1,03 & 1,11 & 1,07 & 87 & 82 & 84,5 & 190 & 174 & 182,0 & 0,53 & 0,42 & 0,48 & 2,43 & 2,31 & 2,37 \\
\hline 12 & X05 TH 69 & 51,54 & 46,22 & 48,88 & 101,4 & 95,22 & 98,33 & 0,50 & 0,49 & 0,50 & 0,97 & 1,06 & 1,02 & 90 & 85 & 87,5 & 190 & 184 & 187,0 & 0,5 & 0,49 & 0,50 & 2,25 & 2,40 & 2,33 \\
\hline 13 & X05 TH 21 & 49,80 & 43,79 & 46,80 & 99,2 & 87,59 & 93,41 & 0,49 & 0,44 & 0,47 & 0,99 & 1,00 & 1,00 & 88 & 83 & 85,5 & 186 & 178 & 182,0 & 0,48 & 0,45 & 0,47 & 2,26 & 2,36 & 2,31 \\
\hline 14 & X05 TH 21 & 59,72 & 50,61 & 55,17 & 115,2 & 100,1 & 107,67 & 0,56 & 0,49 & 0,53 & 0,93 & 0,98 & 0,96 & 96 & 90 & 93,0 & 202 & 190 & 196,0 & 0,56 & 0,50 & 0,53 & 2,22 & 2,25 & 2,24 \\
\hline 15 & ENA 144-10 & 44,19 & 49,44 & 46,82 & 89,4 & 95,82 & 92,60 & 0,45 & 0,46 & 0,46 & 1,02 & 0,94 & 0,98 & 84 & 87 & 85,5 & 180 & 186 & 183,0 & 0,46 & 0,49 & 0,48 & 2,35 & 2,32 & 2,34 \\
\hline 16 & ENA 144-11 & 51,22 & 45,04 & 48,13 & 103,0 & 87,24 & 95,13 & 0,52 & 0,42 & 0,47 & 1,01 & 0,94 & 0,98 & 90 & \begin{tabular}{|l|}
85 \\
\end{tabular} & 87,5 & 192 & 178 & 185,0 & 0,52 & 0,43 & 0,48 & 2,30 & 2,23 & 2,27 \\
\hline 17 & ENA 144-16 & 48,36 & 45,72 & 47,04 & 95,68 & 91,77 & 93,73 & 0,47 & 0,46 & 0,47 & 0,98 & 1,01 & 1,00 & 87 & 85 & 86,0 & 184 & 182 & 183,0 & 0,47 & 0,47 & 0,47 & 2,27 & 2,34 & 2,31 \\
\hline 18 & Hasanbey & 48,81 & 46,52 & 47,67 & 96,18 & 92,71 & 94,45 & 0,47 & 0,46 & 0,47 & 0,97 & 0,99 & 0,98 & 87 & 86 & 86,5 & 184 & 181 & 182,5 & 0,47 & 0,45 & 0,46 & 2,27 & 2,25 & 2,26 \\
\hline 19 & Seçkin & 44,62 & 38,94 & 41,78 & 91,53 & 80,25 & 85,89 & 0,47 & 0,41 & 0,44 & 1,05 & 1,06 & 1,06 & 84 & \begin{tabular}{|l|}
80 \\
\end{tabular} & 82,0 & 182 & 171 & 176,5 & 0,48 & 0,41 & 0,45 & 2,41 & 2,37 & 2,39 \\
\hline 20 & İnci & 39,29 & 33,36 & 36,33 & 75,18 & 65,18 & 70,18 & 0,36 & 0,32 & 0,34 & 0,91 & 0,95 & 0,93 & 80 & 73 & 76,5 & 166 & 156 & 161,0 & 0,36 & 0,33 & 0,35 & 2,20 & 2,43 & 2,32 \\
\hline
\end{tabular}




\section{Çukurova Bölgesinde Bazı Nohut (Cicer arietinum L.) Çeşit ve Hatlarında Verim ve Kalite Özelliklerinin \\ Değerlendirilmesi}

Çizelge 4. Adana Lokasyonunda Bazı Nohut Hatlarında Kalite Özellik ve Elek Değerleri (2014-2015)

\begin{tabular}{|c|c|c|c|c|c|c|c|c|c|c|c|c|c|c|c|c|c|}
\hline \multirow[t]{2}{*}{$\begin{array}{l}\text { Sira } \\
\text { No }\end{array}$} & \multirow[t]{2}{*}{$\begin{array}{l}\text { Hat ve } \\
\text { Çeşitler }\end{array}$} & \multicolumn{4}{|c|}{2014 Elek Değerleri (\%) } & \multicolumn{3}{|c|}{2015 Elek Değerleri (\%) } & \multicolumn{3}{|c|}{$\begin{array}{c}\text { 2014-2015 Ortalama Elek } \\
\text { Değerleri (\%) }\end{array}$} & \multicolumn{3}{|c|}{$\begin{array}{c}\text { Nitrojen } \\
(\%)\end{array}$} & \multicolumn{3}{|c|}{$\begin{array}{l}\text { Protein } \\
(\%)\end{array}$} \\
\hline & & $9 \mathrm{~mm}$ & $8 \mathrm{~mm}$ & $7 \mathrm{~mm}$ & $6 \mathrm{~mm}$ & $9 \mathrm{~mm}$ & $8 \mathrm{~mm}$ & $7 \mathrm{~mm}$ & $9 \mathrm{~mm}$ & $8 \mathrm{~mm}$ & $7 \mathrm{~mm}$ & 2014 & 2015 & ort & 2014 & 2015 & ort \\
\hline 2 & X201 TH165 & 11,36 & 45,42 & 36,52 & 6,56 & 44,35 & 52,44 & 3,21 & 27,86 & 48,93 & 19,87 & 3,2001 & 2,93 & 3,07 & 20,00 & 18,30 & 19,15 \\
\hline 3 & EN 808 & 39,74 & 52,71 & 7,17 & 0,4 & 31,21 & 60,19 & 8,6 & 35,48 & 56,45 & 7,89 & 3,4338 & 3,17 & 3,30 & 21,46 & 19,81 & 20,64 \\
\hline 4 & EN 766 & 42,27 & 48,75 & 8,41 & 1,45 & 22,47 & 62,95 & 14,78 & 32,37 & 55,85 & 11,60 & 3,6129 & 3,01 & 3,31 & 22,58 & 18,83 & 20,71 \\
\hline 5 & EN 952 & 30,84 & 56,30 & 12,57 & 0,34 & 52,29 & 45,3 & 2,43 & 41,57 & 50,80 & 7,50 & 3,4440 & 3,01 & 3,23 & 21,52 & 18,83 & 20,18 \\
\hline 6 & Ç-100-2-2 & 11,23 & 71,22 & 17,72 & 0,44 & 25,19 & 66,8 & 8,01 & 18,21 & 69,01 & 12,87 & 3,4776 & 3,09 & 3,28 & 21,73 & 19,29 & 20,51 \\
\hline 7 & ENA 8-2 & 46,69 & 44,51 & 8,27 & 0,44 & 15,59 & 67,44 & 17,01 & 31,14 & 55,98 & 12,64 & 3,4980 & 3,03 & 3,26 & 21,86 & 18,93 & 20,40 \\
\hline 8 & FLIP 03-108C & 42,84 & 51,68 & 5,37 & 0,19 & 27,51 & 66,88 & 5,65 & 35,18 & 59,28 & 5,51 & 3,4695 & 3,31 & 3,39 & 21,68 & 20,69 & 21,19 \\
\hline 9 & FLIP 03-42C & 39,73 & 56,02 & 4,40 & 0 & 38,28 & 57,11 & 4,62 & 39,01 & 56,57 & 4,51 & 3,6400 & 3,10 & 3,37 & 22,75 & 19,37 & 21,06 \\
\hline 10 & FLIP 03-21C & 31,54 & 65,94 & 2,51 & 0 & 22,75 & 72,43 & 4,84 & 27,15 & 69,19 & 3,68 & 3,7953 & 3,08 & 3,44 & 23,72 & 19,23 & 21,48 \\
\hline 11 & X05 TH 80 & 43,79 & 46,45 & 9,81 & 0 & 41,07 & 50,9 & 8,05 & 42,43 & 48,68 & 8,93 & 3,3463 & 2,98 & 3,16 & 20,91 & 18,65 & 19,78 \\
\hline 13 & X05 TH 21 & 63,49 & 33,72 & 2,65 & 0 & 59,4 & 37,5 & 3,15 & 61,45 & 35,61 & 2,90 & 3,4143 & 3,13 & 3,27 & 21,33 & 19,59 & 20,46 \\
\hline 14 & X05 TH 21 & 89,92 & 9,97 & 0,74 & 0 & 84,59 & 14,95 & 0,51 & 87,26 & 12,46 & 0,63 & 3,8006 & 3,07 & 3,44 & 23,75 & 19,18 & 21,47 \\
\hline 15 & ENA $144-10$ & 16,35 & 61,07 & 21,29 & 1,17 & 84,58 & 13,82 & 1,61 & 50,47 & 37,45 & 11,45 & 3,4254 & 2,85 & 3,14 & 21,40 & 17,83 & 19,62 \\
\hline 16 & ENA $144-11$ & 44,66 & 48,68 & 6,86 & 0 & 40,55 & 55,53 & 3,98 & 42,61 & 52,11 & 5,42 & 3,4438 & 2,81 & 3,13 & 21,52 & 17,57 & 19,55 \\
\hline 17 & ENA 144-16 & 33,72 & 54,28 & 11,79 & 0,42 & 42,31 & 55,22 & 2,55 & 38,02 & 54,75 & 7,17 & 3,3341 & 2,98 & 3,16 & 20,83 & 18,61 & 19,72 \\
\hline 18 & HASANBEY & 31,97 & 60,94 & 6,89 & 0,39 & 16,92 & 79,08 & 4,02 & 24,45 & 70,01 & 5,46 & 3,4488 & 2,92 & 3,18 & 21,55 & 18,23 & 19,89 \\
\hline 19 & SEÇKİN & 39,24 & 56,50 & 4,45 & 0 & 14,66 & 75,82 & 9,55 & 26,95 & 66,16 & 7,00 & 3,6958 & 2,94 & 3,32 & 23,09 & 18,40 & 20,75 \\
\hline 20 & İNCİ & 15,15 & 73,57 & 11,14 & 0,17 & 9,1 & 63,12 & 27,78 & 12,13 & 68,35 & 19,46 & 3,5554 & 3,00 & 3,28 & 22,22 & 18,76 & 20,49 \\
\hline
\end{tabular}




\section{Çukurova Bölgesinde Bazı Nohut (Cicer arietinum L.) Çeşit ve Hatlarında Verim ve Kalite Özelliklerinin Değerlendirilmesi}

$\mathrm{Bu}$ nedenle de 1slahta iri taneli çeşitlerin Ascochyta yanıklığı hastalığına toleransının çok iyi belirlenmesi gerekmektedir. (Mart,2001, Akem, 1999) nohut bitkisindeki Ascochyta yanıklığını ilk olarak 1911 yılında Butler'ın tanımlandığını belirtmiştir. Ayrıca bitkilere zarar veren etmenin asıl kaynağının piknio sporların eseri olduğunu ileri sürmüştür. (Vail, 2005) Ascochyta yanıklığ1 etmeninin nohut üretimi ve verimliliğini olumsuz etkilediğini belirtmiştir. Ayrıca Vail (2005) eşeyli dönemde genetik çeşitliliğin meydana geldiğini belirten bir çalışma daha yapmıştır. Buna ek olarak bu olgunun patojenin patotiplerinin oluşmasına neden olduğunu da belirtmiştir.

İki yıllık ortalamalara göre, bu çalışmada yer alan hatlar arasında X05 TH 21 hattı kuru ağırlık, elek analizlerinden 9 nolu elekte (\%87.26), Adana1 hattı ise kuru ağırlık $(56.83 \mathrm{~g})$, yaş ağırlık $(110.9 \mathrm{~g})$, şişme kapasitesi $(0.53 \mathrm{ml} /$ tane $)$ bakımından diğer hatlara göre yüksek değerleri vererek ön plana çıkmışlardır. Protein analiz değerleri ise en yükssek FLIP 03-21C hattından \%21.48 elde edilmiştir.

\section{Teşekkür}

Bu Çalışma, TÜBİTAK 1003 Projesi, 1130070 nolu proje ile desteklenmiştir. TÜBİTAK'a katk1 ve maddi desteklerinden dolayı çok teşekkür ederiz.

\section{Kaynaklar}

Anonymous, (2021) FAO. https:// www. fao. org/ faostat/

Açikgöz, N. (1987) Nohut Tarımı, Ege Bölge Zirai Arş. Ens. Müd. Yayın No: 76, Menemen-İzmir, $25 \mathrm{~s}$.

Akem, C. (1999) Ascochyta blight of chickpea: present status and future priorities.

International Journal of Pest Management, 45, 131137.

Anlarsal, A.E.,C. Yücelve D. Özveren.(1999) Çukurova koşullarında bazı nohut hatlarının verim ve verimle ilgili özelliklerinin saptanması üzerinde biraraştırma. Türkiye 3 . Tarla Bitkileri Kongresi Cilt III (Çayır Mera
Yem Bitkileri ve Yemeklik Tane Baklagiller), s.342- 347,15-18 Kasım,Adana. Atikyılmaz, N. (1997) Kışlık ve Yazlık Nohut Ekiminde Verim ve Verim Bileşenleri Arasındaki İlişkileri ile Bazı Kalite Özelliklerinin Saptanması Üzerine Bir Araştırma. Yüksek Lisans Tezi (Basılmamış). Dicle Üniversitesi, 53 s., Diyarbakır.

Babagil G.E.2011., Erzurum ekolojik koşullarında bazı nohut (CicerarietinumL.) çeşitlerinin verim ve verim özelliklerinin incelenmesi. Anadolu Tarım Bilim. Derg., 2011,26(2):122- 127.

Bakoğlu A. (2009) Elazığ ekolojik koşullarında bazı nohut (CicerarietinumL.) çeşitlerinin verim ve verim öğeleri üzerine biraraştırma. Harran Üniversitesi Ziraat Fakültesi Dergisi. 2009 13(1):1-6

Bejiga, G. and Tollu, A. (1982) The Influence of Plantings Dateson the Yield of Three Chickpea (Cicer Khorgade, P.W.,Narkhede, M.N. and Raut, S.K. 1985. Genetic Variability Studies in Chickpea. International Chickpea Newsletter, 12; 1213.

Chen W, Coyne CJ, Peever TL, Muehlbauer FJ (2004) Characterization of chickpea differentials for pathogenicity assay of Ascochyta blight and identification of chickpea accessions resistant to Didymella rabiei. Plant Pathol 53:759-769

Eser, D. (1978) Yemeklik Tane Baklagiller. Ankara Üniversitesi Ziraat Fakültesi Ders Rotosu, 98 s.,Ankara.

Gül, M. K., Egesel, C. Ö., Kahrıman, F., Tayyar, Ş. (2006) Çanakkale Yöresinde Nohut Bitkisinin Kışlık Olarak Yetiştirilebilme Olanakları. Uludag.Üniv.Zir.Fak.Derg. (2006) 20(1): 57-66

Kocalar, H., Kafadar F. N., Ozkan, A., Talapov,T. Demirel, Ö., Anay, A., Mart, D., Can, C.(2020) Current Distribution and Virulence of Fusarium oxysporum f. sp. ciceris in Turkey; Legume Research - An International Journal, 10.18805/LR-520 


\section{Çukurova Bölgesinde Bazı Nohut (Cicer arietinum L.) Çeşit ve Hatlarında Verim ve Kalite Özelliklerinin Değerlendirilmesi}

Mart, D., Anlarsal,E; (2001) Çukurova Koşullarında Nohutta (Cicerarietinum L.) Bazı Önemli Özellikler Yönünden Genotip $\mathrm{X}$ Çevre İnteraksiyonları ve Uyum Yeteneklerinin saptanması Üzerine Bir Araştırma. Türkiye 4. Tarla Bitkileri Kongresi 17-21 Eylül 2001, Tekirdağ.

Mart, D. (2006) Investigation of relations amang ascochyta blight and plant morphology with multi - regrassion on winter planted chickpea (Cicerarietinum) varieties in the Çukurova region, Ascochyta 2006, 2-6 Temmuz, Le Tronchet, France.

Mart, D.,Çinkaya, N., T. Karaköy and A. Keçeli, (2010) Adaptation of Registered Chickpea (Cicer arietinum L)Varieties To Cukurova Region And Investigation Of Quality Values In Regional Conditions, Book Abstracts, 5th International Food Legumes Research Conferance (IFLRCV) \&7th European Conferance On Grain Legumes (AEP VII); Legumes For Global Health Legume Crops And Products For Food, Feed And Environmental Benefits April 2630, 2010- Antalya.

Mart, D.,Yücel, D., Türkeri, M. 2015. Çukurova Bölgesinde Nohut (CicerarietinumL.) GenotiplerininKışlık Ekim Zamanında Verim Ve Morfolojik Özelliklerinin Değerlendirilmesi. 11.Tarla Bitkileri Kongresi, 19-23Eylül 2015,Çanakkale.

Muehlbauer, F.J.and K.B. Singh, 1987, Genetics of chickpea. P. 99-125.In M.C. Saxena and K.B. Singh (ed) Thechickpea, CAB Int, Oxon UK.

Nalçacı,N. Feyza Nur Kafadar,FN, Özkan,A. Turan,A Başbuğa, S. Anay,A. Mart,D Öğut,E. Sarpkaya,K Atik, O, Can C.(2021); Epiphytotics of chickpea Ascochyta blight in Turkey as influenced by climatic factors; ,Journal of Plant Diseases and Protection,https://doi.org/10.1007/s41348021-00458-7;

Nalcaci, N., Turan A., Basbuga S., Kafadar F. N., Isler D.Ceyhan E, Anay A., Mart D., Ogut E., Sarpkaya K., and Can C. (2021) Virulence and Mating Type Distribution of Didymella rabiei in Chickpea Growing Areas of Turkey, J. Agr. Sci. Tech. (2021) Vol. 23(1): 209-220 (JAST)

Phadnis, B.A., A.P. Ekbote And S.S. Ainchwar. (1970) Path-Coefficient Analysis in Gram (C.arietinum). Bibloography of Chickpea Genetics andBreeding., 115:915.

Reddy MV, Kabbabeh S. (1985) Pathogenic variability in Ascochyta rabiei (Pass.) Lab. in Syria and Lebanon. Phytopathologica Med 24:265-266

Reddy, M. V. and Sing, K. B. (1990) Relationship between Ascochyta Blight Severity and Yield Losing Chickpea and Identification of Resistant Lines. Phytopathol. Med., 29: 3238.

Saxena, M.C., 1980.RecentAdvences İn ChickpeaAgronomy. InProceedings Of The First International Workshop on Chickpea Improvement, 28 Feb- 2 Mar 1979. Icrisat, Hyderabat, India, s.89-96.

Slim, S.N.,Saxena. M.C.,1993. Adaptation of Spring-Sown chickpea to the Mediterranean Basin. I Response to Moisture Supply, Field Crops Research, 34, 121-136.

Slim, S.N.,Saxena. M.C.,1993. Adaptation of Spring-Sown chickpea to the Mediterranean Basin.II. Factors 1nfluencing Yield under Drought, Field Crops Research, 34, 137146.

Şehirali, S., 1988. Yemeklik Tane Baklagiller. Ank. Ün. Zir. Fak..yayınları :1089, Ankara, $435 \mathrm{~s}$.

Şehirali, S.,2002. Tohumluk ve teknolojisi, Trakya Ün. Ziraat Fak., Tarla Bitkileri Böl. İstanbul.

Singh, K.B., Williams, P.C. and Nakkoul, H. 1990. Influence of Growing Season, Location and Planting Time on Some Quality Parameters of Kabuli Chickpea. Journal of The Science of Food and Agriculture, 55(4);429-441.

Tripathi, H.P. and Singh, S.N. 1985. Performance of Chickpea Varieties under Different Dates of Sowing. International Chickpea Newsletter, 13;11-13. 
Çukurova Bölgesinde Bazı Nohut (Cicer arietinum L.) Çeşit ve Hatlarında Verim ve Kalite Özelliklerinin Değerlendirilmesi

Vail, S. L., (2005). Population studies of Ascochyta rabiei on chickpea in Saskatchewan, M. S. Thesis, University of Saskatchewan, Dept. Of Plant Sciences, Saskatoon. 
Çukurova Bölgesinde Bazı Nohut (Cicer arietinum L.) Çeşit ve Hatlarında Verim ve Kalite Özelliklerinin Değerlendirilmesi 